\title{
Immunotherapy-Induced Colitis: An Emerging Problem for the Hospitalist
}

\author{
Julian A. Marin-Acevedo, MD¹, Dana M. Harris, MD²*, M. Caroline Burton, MD³
}

${ }^{1}$ Mayo School of Graduate Medical Education, Mayo Clinic, Jacksonville, Florida; ${ }^{2}$ Division of Community Internal Medicine, Mayo Clinic, Jacksonville, Florida; ${ }^{3}$ Division of Hospital Internal Medicine, Mayo Clinic, Jacksonville, Florida.

Since their introduction for melanoma treatment, the use of immune checkpoint inhibitors (ICls) has rapidly expanded. Though their impact on survival is irrefutable, these medications have been associated with autoimmune-like adverse events related to their ability to induce the immune system. One of the most commonly affected organ systems is the gastrointestinal (GI) tract, in which manifestations range from mild diarrhea to severe colitis with intestinal perforation. Because of the increased use of $\mathrm{ICls}$, hospitalists are caring for an increasing number of patients experiencing their adverse events. We present a case-oriented review of the $\mathrm{Gl}$ adverse events associated with the use of ICls to familiarize the hospitalist with their mechanism of action and potential complications and to emphasize the importance of early diagnosis and treatment to decrease morbidity and mortality. Journal of Hospital Medicine 2018;13: 413-418. Published online first February 7, 2018. (C) 2018 Society of Hospital Medicine mmune checkpoint inhibitors (ICls), a form of immunotherapy, have changed the management of cancer since their introduction in 2011. ${ }^{1}$ They were initially tested on melanoma. $^{2}$ Their use in the advanced stages of the disease demonstrated a 2 -year survival of $18 \%$ compared with $5 \%$ by using other therapies. ${ }^{3}$ Similar results were observed in nonsmall cell lung carcinoma (NSCLC); the overall survival benefit was 3 months with the use of $\mathrm{ICls}$ compared with traditional chemotherapy (42\% and $24 \%$ at 1 year, respectively). ${ }^{4}$ Antitumor activity has also been seen in the treatment of other malignancies, including renal cell carcinoma, ${ }^{5}$ bladder carcinoma, ${ }^{6,7}$ head and neck carcinoma, ${ }^{8}$ colorectal cancer, ${ }^{9}$ Hodgkin lymphoma, ${ }^{10}$ and, more recently, hepatocellular carcinoma. ${ }^{11}$ The use of $\mathrm{ICls}$ has also been linked to serious complications. ${ }^{12}$ Although the skin, kidneys, lungs, and endocrine and nervous systems may be affected, complications of the gastrointestinal (GI) tract are frequent and can be life-threatening. ${ }^{12-16}$ We performed a thorough review of the literature to familiarize hospitalists with the mechanism of action and uses of $\mathrm{ICls}$, the clinical presentation of their GI toxicity, and the current recommendations regarding diagnosis and treatment.

\section{CASE PRESENTATION}

A 66-year-old man was admitted to our institution with a 1-week history of severe, diffuse abdominal pain and profuse watery diarrhea. He reported having more than 8 watery bowel movements per day and denied fever, recent travel, ill contacts, or

*Address for correspondence: Dana M. Harris, MD, Division of Community Internal Medicine, Mayo Clinic, 4500 San Pablo Road, Jacksonville, FL 32224; Telephone: 904-953-0657; Fax: 904-953-0655; E-mail: harris.dana@mayo.edu

Received: July 25, 2017; Revised: October 13, 2017;

Accepted: October 26, 2017

(c) 2018 Society of Hospital Medicine DOI 10.12788/jhm.2925 ingestion of undercooked food. He had a history of metastatic melanoma and was undergoing treatment with both nivolum$\mathrm{ab}$ and ipilimumab; the drugs were started 6 weeks prior to presentation. Physical examination revealed a heart rate of 110 beats/minute while supine and 123 beats/minute while standing, blood pressure of $112 / 69 \mathrm{~mm} \mathrm{Hg}$ while supine and $92 / 62 \mathrm{~mm} \mathrm{Hg}$ while standing, and a temperature of $37.2^{\circ} \mathrm{C}$. He was in mild distress and had dry oral mucosa. Abdominal examination revealed hyperactive bowel sounds and mild diffuse abdominal tenderness with no guarding or rebound. His extremities were cool, but peripheral pulses were present. Initial laboratory results included a hemoglobin level of $15.3 \mathrm{~g} /$ $\mathrm{dL}$ (range 12.0-16.0 mg/dL), white blood cell count $14.2 \times 10^{9} / \mathrm{L}$ (range $4.5-11.0 \times 10^{9} / \mathrm{L}$ ), and platelet count $236 \times 10^{\circ} / \mathrm{L}$ (range $150-400 \times 10^{9} / \mathrm{L}$ ); other test results included a sodium level of $130 \mathrm{mmol} / \mathrm{L}$ (range $135-145 \mathrm{mmol} / \mathrm{L}$ ), potassium $2.3 \mathrm{mmol} / \mathrm{L}$ (range 3.5-5.5 mmol/L), serum creatinine $2.2 \mathrm{mg} / \mathrm{dL}$ (range 0.8 $1.3 \mathrm{mg} / \mathrm{dL}$ ), blood urea nitrogen $72 \mathrm{mg} / \mathrm{dL}$ (range $8-21 \mathrm{mg} / \mathrm{dL}$ ), and serum venous lactate $5.9 \mathrm{mmol} / \mathrm{L}$ (range 0.9-1.7 $\mathrm{mmol} / \mathrm{L}$ ).

\section{MECHANISM OF ACTION AND USES OF ICIS}

T-cell lymphocytes play a pivotal role in acquired immunity, but their function requires an appropriate balance between stimulatory and inhibitory signals to prevent autoimmunity. ${ }^{17} \mathrm{Im}$ mune checkpoint molecules are used by the immune system to assist with this balance. ${ }^{18}$ Although several of these molecules exist, the cytotoxic T-lymphocyte antigen-4 (CTLA-4) and programmed cell death-1 (PD-1) are among the most widely studied. ${ }^{12}$

Activation or inhibition of $T$ cells depends on the interaction of their receptors with ligands located on the surface of other cells. Both CTLA-4 and PD-1 are receptors located on the surface of T-cell lymphocytes that inhibit the function of $\mathrm{T}$ cells after binding with their ligands. ${ }^{19-21}$ Cancer cells often use this mechanism to avoid immune recognition and promote their survival. 18,21,22 Importantly, ligands that bind CTLA-4 are 


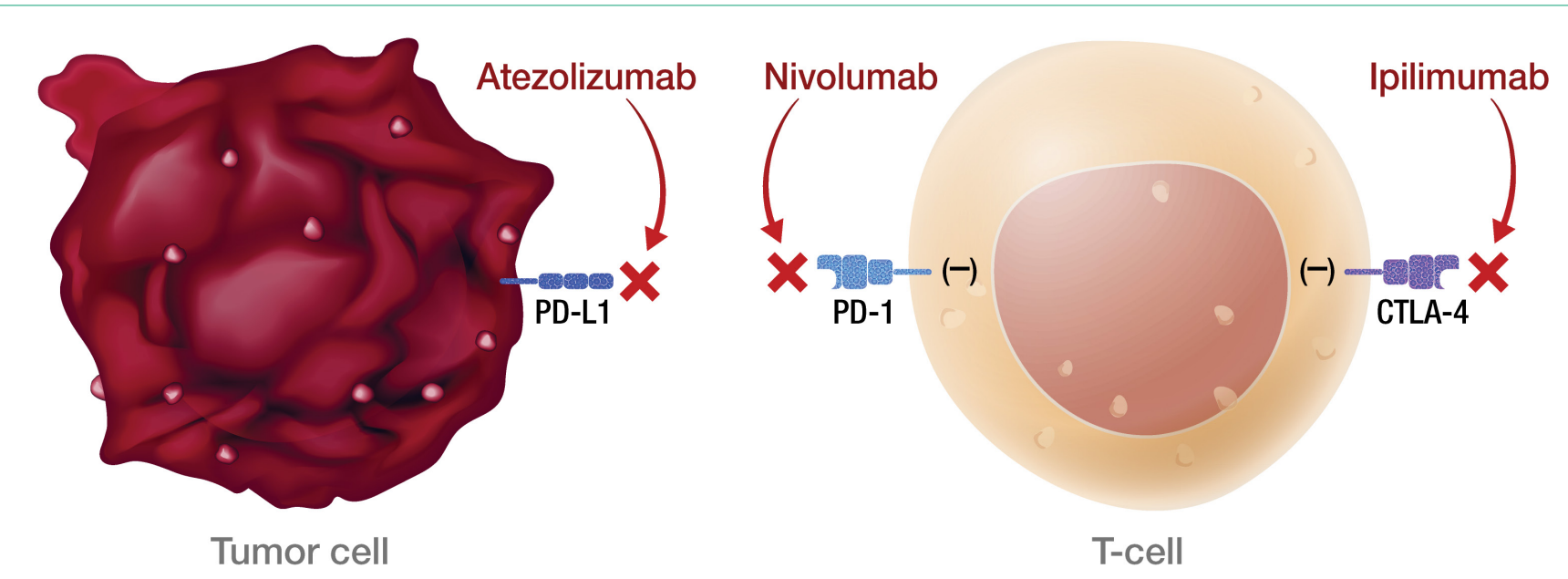

FIG. T-cell interacting with antigen-presenting cells and a tumor cell. PD-1/PD-L1 receptor/ligand and CTLA-4 receptor/ligand interaction lead to negative signal and blockage of T-cell activation. Used with permission of Mayo Foundation for Medical Education and Research. All rights reserved. Abbreviations: CTLA-4, cytotoxic T-lymphocyte antigen-4; PD-1, programmed cell death-1; PD-L1, programmed cell death ligand-1.

expressed by numerous tissues throughout the body, contrary to ligands that bind to PD-1 (PD-L1 or PD-L2), which are more specific to tumor cells (Figure). ${ }^{21-23} \mathrm{ICls}$ are monoclonal antibodies that block these pathways and increase T-cell activity. ${ }^{18}$

Ipilimumab is a monoclonal antibody directed against CTLA4. ${ }^{24}$ After demonstrating survival benefits in patients with unresectable and metastatic melanoma, ipilimumab was the first $\mathrm{ICl}$ approved for use by the US Food and Drug Administration (FDA) ${ }^{1,3}$ Another monoclonal antibody directed against CTLA4, tremelimumab, is not currently approved for use by the FDA.

Pembrolizumab and nivolumab are monoclonal antibodies against PD-1. The FDA approved them for the treatment of advanced melanoma in $2014^{17}$ and metastatic NSCLC in $2015 .{ }^{12}$ Nivolumab was also approved for the treatment of renal cell carcinoma and for advanced-stage melanoma in combination with ipilimumab. ${ }^{12,17}$ Atezolizumab, avelumab, and durvalumab are PD-L1 inhibitors. All 3 are approved by the FDA for treatment of advanced urothelial carcinoma. ${ }^{25-27}$ Atezolizumab is also approved for the treatment of metastatic NSCLC, ${ }^{28}$ and avelumab is approved for treatment of metastatic Merkel cell carcinoma. ${ }^{29}$ Table 1 summarizes the medications, their target, and FDA-approved indications. 1,12,17,26,27,29,30

\section{TOXIC PROFILE}

Because of the sustained T-cell activation, ICls have been associated with autoimmune-like toxicities known as immune-related adverse events (irAEs). ${ }^{19,31}$ Because the PD-1/PD-L1 pathway is more tumor-specific than the CTLA-4 pathway, ${ }^{21-23}$ there is a higher incidence of serious irAEs seen with ipilimumab, reported to be around 27\%. ${ }^{18,22}$ Furthermore, the risk of developing irAEs is dose-dependent and can increase up to $55 \%$ when anti-CTLA-4 are used with other ICls such as nivolumab. ${ }^{13,32-34}$

The skin and $\mathrm{Gl}$ tract are the most commonly involved organs. ${ }^{14-16}$ Skin is affected in $50 \%$ of patients receiving ipilimumab and $40 \%$ of patients on nivolumab or pembrolizumab, often in the form of a rash or pruritus. ${ }^{12,35-37}$ The rash is often
TABLE 1. Summary of $\mathrm{ICl}$ Target and Indications

\begin{tabular}{lll}
\hline Name of the Drug & Target Receptor & FDA Approval for Use \\
\hline Ipilimumab (Yervoy) & CTLA-4 & Advanced melanoma \\
\hline Tremelimumab & CTLA-4 & Not yet approved \\
\hline Nivolumab (Opdivo) & PD-1 & $\begin{array}{l}\text { Advanced melanoma, NSCLC, RCC, CHL, } \\
\text { HNSCC, advanced urothelial carcinoma, CRC }\end{array}$ \\
\hline Pembrolizumab (Keytruda) & PD-1 & $\begin{array}{l}\text { Advanced melanoma, NSCLC, HNSCC, CHL, } \\
\text { advanced urothelial carcinoma, advanced gastric } \\
\text { cancer, microsatellite instability-high cancer }\end{array}$ \\
\hline Atezolizumab (Tecentriq) & PD-L1 & NSCLC and advanced urothelial cancer \\
\hline Avelumab (Bavencio) & PD-L1 & Metastatic MCC, advanced urothelial cancer \\
\hline Durvalumab (Imfinzi) & PD-L1 & Advanced urothelial carcinoma
\end{tabular}

NOTE: Table based on references 1, 12, 17, 26, 27, 29, and 30. Abbreviations: $\mathrm{CHL}$, Classical Hodgkin Lymphoma; CRC, colorectal cancer; CTLA-4, cytotoxic T-lymphocyte antigen-4; HNSCC, head and neck squamous cell carcinoma; ICl, immune checkpoint inhibitors; $\mathrm{MCC}$ Merkel cell carcinoma; NSCLC, nonsmall cell lung cancer; PD-1, programmed cell death-1; PD-L1, programmed cell death ligand-1; RCC, renal cell cancer.

described as faintly erythematous, reticular, and maculopapular and typically affects the trunk and extremities. ${ }^{38}$ Importantly, these events usually occur within the first 2 weeks of treatment, and fewer than $5 \%$ are severe. ${ }^{12,36,39}$ A higher percentage of severe adverse events occurs in the $\mathrm{Gl}$ tract, with a reported incidence of $12 \%$. 3,14,36,39

\section{CLINICAL PRESENTATION}

Although any portion of the $\mathrm{Gl}$ tract can be affected by $\mathrm{ICls}$, the lower $\mathrm{Gl}$ tract is most commonly involved. Clinical signs include watery diarrhea, colitis, and enteritis. ${ }^{15,19}$ Less commonly, the upper Gl tract is involved, and clinical manifestations include aphthous ulcers, esophagitis, and gastritis. ${ }^{40,41} \mathrm{Gl}$ symptoms usually begin 6 weeks after the initial dose of $\mathrm{ICls}$ and typically follow cutaneous manifestations. ${ }^{15,20,36,37}$ However, they can occur as late 
TABLE 2. Common Terminology Criteria for Adverse Events (CTCAEs)

\begin{tabular}{|c|c|c|c|c|c|}
\hline \multirow[b]{2}{*}{ Adverse Event } & \multicolumn{5}{|l|}{ Grade } \\
\hline & 1 & 2 & 3 & 4 & 5 \\
\hline Diarrhea & $\begin{array}{l}\text { Increase of }<4 \text { stools per day } \\
\text { over baseline; mild increase in ostomy output } \\
\text { compared with baseline }\end{array}$ & $\begin{array}{l}\text { Increase of } 4-6 \text { stools per day } \\
\text { over baseline; IV fluids }<24 \text { hours; } \\
\text { not interfering with } A D L\end{array}$ & $\begin{array}{l}\text { Increase of } \geq 7 \text { stools per day } \\
\text { over baseline; incontinence; } \\
\text { IV fluids } \geq 24 \text { hours; hospitalization; } \\
\text { interfering with } A D L\end{array}$ & $\begin{array}{l}\text { Life-threatening consequences } \\
\text { (eg, hemodynamic collapse) }\end{array}$ & Death \\
\hline Colitis & $\begin{array}{l}\text { Asymptomatic, pathologic, or radiographic } \\
\text { findings only }\end{array}$ & $\begin{array}{l}\text { Abdominal pain; mucus or blood } \\
\text { in stool }\end{array}$ & $\begin{array}{l}\text { Abdominal pain; fever; change } \\
\text { in bowel habits with ileus; } \\
\text { peritoneal signs }\end{array}$ & $\begin{array}{l}\text { Life-threatening consequences } \\
\text { (eg, perforation, bleeding, ischemia, } \\
\text { necrosis, toxic megacolon) }\end{array}$ & Death \\
\hline
\end{tabular}

NOTE: Adapted from the Cancer Therapy Evaluation Program, National Cancer Institute (NCI) Common Terminology Criteria for Adverse Events v3.0 (CTCAE).57 Abbreviations: ADL, activities of daily life; IV, intravenous.

as 4 months after the last dose. ${ }^{19}$ Watery, nonbloody diarrhea is the most common presentation of $\mathrm{Gl}$ involvement, occurring in $19 \%$ of patients receiving anti-PD-1/PD-L1 and 33\% receiving anti-CTLA-4 medications. ${ }^{19,37}$ When patients receive both therapies, the incidence rate increases to $44 \% .^{32}$ The clinical severity of diarrhea can be graded on a scale of 1 to 5 according to the Common Terminology Criteria for Adverse Events (CTCAE) (Table 2). ${ }^{42}$ Though most patients have mild disease (grade 1 or 2), close to $3 \%$ develop severe diarrhea (grade 3 or higher) with electrolyte disturbances and weight loss..$^{14,20}$

Colitis, defined by either the presence of symptoms or radiologic findings suggestive of inflammation, occurs less often than diarrhea alone, with a reported incidence of $2.3 \%$. $^{37,43}$ This incidence increases to almost $12 \%$ when anti-CTLA- 4 and anti-PD-1/PD-L1 are combined. ${ }^{32}$ Colitis symptoms include abdominal pain (20\%), nausea and vomiting (15\%), fever (12\%), and, less often, bloody diarrhea or rectal bleeding. ${ }^{19,20}$ Colitis severity is graded according to the CTCAE (Table 2). ${ }^{42}$ Most patients have mild colitis (grade 1 or 2). ${ }^{19}$ The risk for developing severe colitis (grade 3 or higher) is almost 10 times higher with the use of anti-CTLA-4 compared with anti-PD-1/PD-L1 agents. ${ }^{43}$ Patients with severe disease are at risk of developing life-threatening complications, such as ileus, toxic megacolon, bowel ischemia, necrosis, or even perforation, which has been reported in up to $5 \%$ of patients with colitis because of ipilimumab. ${ }^{13,17}$

\section{CASE APPROACH STRATEGY}

Based on the patient's symptoms, physical findings, and temporal relationship to $\mathrm{ICl}$ therapy, he was believed to have immune-mediated colitis. Stool studies, including those looking for ova and parasites, Clostridium difficile polymerase chain reaction (PCR), and stool cultures were negative.

\section{DIAGNOSIS}

In a patient undergoing $\mathrm{ICl}$ treatment who has diarrhea, the initial assessment should exclude C. difficile and Salmonella by stool culture, PCR, or pathogenic antigens. ${ }^{19}$ Cytomegalovirus reactivation should also be considered. Immune-mediated colitis and infection can coexist; thus, a positive infectious etiology does not rule out the presence of immune colitis or vice versa. ${ }^{44}$ Fecal calprotectin, a marker of neutrophil-associated inflammation, is nonspecific for $\mathrm{ICl}$-induced colitis; however, it may help to distinguish inflammatory from noninflammatory diarrhea. ${ }^{33,45}$

No clear guideline exists for the use of abdominal imaging. Some experts suggest using computed tomography in patients with severe, persistent, or progressive symptoms in order to exclude bowel obstruction, toxic megacolon, or perforation. ${ }^{19,46}$

In patients with typical symptoms, and after infectious etiologies are ruled out, empiric use of corticosteroids can be initiated without an endoscopic evaluation, which is not necessary to establish a diagnosis and rarely changes management. ${ }^{12,37,47}$ In patients with atypical presentations or for whom the diagnosis remains in question, endoscopic evaluation with biopsies may be required. Macroscopic findings may be similar to those seen with inflammatory bowel disease (IBD), including erythema, edema, ulceration, granularity, or loss of vascular pattern. Although immune-mediated colitis affects the descending colon more often than IBD, this feature and any macroscopic findings are insufficient to make this distinction. ${ }^{20,36}$ Furthermore, the lack of macroscopic abnormalities does not rule out immune-mediated colitis. ${ }^{20}$

When endoscopic biopsies are obtained, histologic findings for anti-CTLA-4 medications (eg, ipilimumab) usually follow 3 patterns: neutrophilic infiltrate (46\%), lymphocytic infiltrate (15\%), and mixed infiltrate (38\%). ${ }^{41}$ Other findings include crypt abscesses and tissue destruction. ${ }^{20}$ No biopsy-specific pattern has been described with anti-PD-1/PD-L1 medications, such as nivolumab or pembrolizumab. ${ }^{18}$ A normal colonic tissue does not exclude the presence of an irAE, as cases of isolated ileitis $^{48}$ or enteritis ${ }^{49}$ without colitis can also occur.

\section{CASE MANAGEMENT STRATEGY}

The patient was started on intravenous (IV) methylprednisolone $2 \mathrm{mg} / \mathrm{kg}$ twice a day. After 48 hours, he still had more than 7 episodes of diarrhea per day, so he was treated with 1 dose of infliximab $5 \mathrm{mg} / \mathrm{kg}$ without stopping corticosteroids. Within 72 hours, the patient's abdominal pain improved and his diarrhea stopped. He was discharged on an 8-week taper of prednisone starting at $1 \mathrm{mg} / \mathrm{kg} /$ day, pneumocystis pneumo- 
TABLE 3. Management of Colitis Induced by ICI Therapy

\begin{tabular}{ll} 
Grade/Other & Management \\
\hline 1 & $\begin{array}{l}\text { Fluid and electrolyte replacement } \\
\text { Colitis diet of the American Dietetic Association } \\
\text { Loperamide, diphenoxylate hydrochloride, or atropine sulfate }\end{array}$ \\
\hline 2 & Same as grade 1 \\
& If persists $>3$ days: oral prednisone $0.5-1 \mathrm{mg} / \mathrm{kg} /$ day tapered over $4-8$ weeks \\
& Consider IV corticosteroids if no improvement \\
\hline $3-4$ & Oral prednisone: $1-2$ mg/kg/day \pm oral budesonide: $9-12$ mg daily \\
If severe symptoms: IV methylprednisolone 2 mg/kg twice a day \\
for $1-2$ days before transitioning to oral corticosteroids \\
If no improvement: infliximab 5 mg/kg single dose \\
Continue slow taper of oral prednisone over $4-8$ weeks
\end{tabular}

Refractory Consider partial/total colectomy

disease/

perforation

NOTE: Abbreviation: IV, intravenous.

nia (PCP) prophylaxis was started, and ICI therapy was discontinued indefinitely.

\section{MANAGEMENT OF COLITIS}

Several principles should be considered in managing immune-mediated colitis: (1) management for adverse events of anti-CTLA-4 and anti-PD-1/PD-L1 should be the same; (2) though guidelines were made for patients with melanoma, they can be used to treat patients with other types of cancer; and (3) treatment should be started as early as possible, ideally within 5 days of symptom onset, as this hastens clinical improvement and decreases the incidence of complications. ${ }^{20}$ Treatment is summarized in Table 3.

Management of grade 1 and 2 colitis is mainly supportive, consisting of fluid and electrolyte replacement, the American Dietetic Association colitis diet, and antimotility agents, such as loperamide, oral diphenoxylate hydrochloride, or atropine sulfate. ${ }^{36,37}$ Persistent grade 2 symptoms (lasting $>3$ days), should prompt initiation of 0.5 to $1 \mathrm{mg} / \mathrm{kg} /$ day of oral prednisone or an equivalent. ${ }^{19}$ If symptoms do not improve with oral corticosteroids, patient hospitalization for IV corticosteroids should be considered. ${ }^{37}$ Importantly, opioids and antidiarrheals may mask the pain and severity of symptoms and, therefore, should be used cautiously. ${ }^{19}$

Patients with grade 3 and 4 colitis ( $\geq 7$ stools per day, severe abdominal pain, or complications) require the use of systemic corticosteroids at a dose of 1 to $2 \mathrm{mg} / \mathrm{kg} /$ day of prednisone or an equivalent. ${ }^{15}$ Patients who fail to respond to prednisone alone may benefit from the addition of oral budesonide at a dose of 9 to $12 \mathrm{mg} /$ day..$^{50}$ In severe cases of colitis, hospitalization may be necessary for IV hydration, electrolyte replacement, and IV methylprednisolone at a starting dose of $2 \mathrm{mg} /$ $\mathrm{kg}$ twice a day for 1 to 2 days before transitioning to oral corticosteroids. ${ }^{12,15}$ Though improvement is usually noted within the first 2 weeks of treatment, prednisone should be slowly tapered over a period of 4 to 8 weeks to ensure complete healing and prevent relapse. ${ }^{20,36}$ Patients who receive an equivalent dose of prednisone $20 \mathrm{mg}$ daily during a period of 4 weeks or more should receive PCP prophylaxis. ${ }^{51}$ Some patients fail to respond to IV corticosteroids despite adequate dosing. Many of these patients have severe disease, possibly because of delayed recognition and initiation of treatment. ${ }^{19}$ As with IBD, the addition of infliximab to corticosteroids at $5 \mathrm{mg} / \mathrm{kg}$ as a single dose is usually successful for this population subset. ${ }^{52-54}$ Although a response is seen within 1 to 3 days, ${ }^{41}$ some patients benefit from an additional dose of infliximab 2 weeks after the initial dose.${ }^{19}$ If sepsis or perforation is suspected at any point, corticosteroids or infliximab should be avoided and antibiotics should be started immediately. ${ }^{15,19}$ Patients with a medically unresponsive disease may require partial or complete colectomy. ${ }^{20}$ The use of prophylactic budesonide to prevent diarrhea or colitis has not been proven effective and should not be used. ${ }^{55}$ Despite complications, mortality from colitis has markedly decreased given the increased awareness of this adverse event, reduction in the time to recognition and treatment, and increased adherence to corticosteroids. ${ }^{12}$

Treating physicians may be delayed in starting appropriate therapy because patients are concerned that using corticosteroids will negatively impact immunotherapy efficacy. Current evidence shows that the use of temporary immunosuppression to treat irAEs does not affect overall survival, efficacy, or time to treatment failure of the $\mathrm{ICl} .{ }^{12,56}$ Restarting $\mathrm{ICl}$ therapy is a complex decision and should always be individualized. In grade 1 and 2 colitis, $\mathrm{ICl}$ therapy is typically restarted after symptoms have improved. ${ }^{5}$ In grade 3 and 4 colitis, $\mathrm{ICl}$ therapy is often permanently discontinued. ${ }^{20}$

\section{CONCLUSION}

ICls have not only increased our understanding of the biology of cancer, but they have also improved survival in advanced stages of malignancies like melanoma, NSCLC, and renal cell carcinoma. The expanding use of these medications increases the likelihood that healthcare providers will encounter patients experiencing their adverse events.

Immune-mediated $\mathrm{Gl}$ adverse events include a wide range of symptoms, from mild diarrhea to severe colitis complicated by perforation and death. Diagnosis requires exclusion of an infectious process. Early recognition and treatment with corticosteroids or another immunosuppressant such as infliximab hastens recovery and decreases complications and mortality. Treatment should be started within 5 days of symptom onset. Corticosteroids should be slowly tapered for no less than 4 weeks to prevent relapse and PCP prophylaxis administered in appropriate patients. Restarting $\mathrm{ICl}$ therapy may be considered in cases of mild colitis, but in severe cases, $\mathrm{ICl}$ therapy is usually discontinued.

Disclosures: Julian Marin-Acevedo, Dana Harris, and M. Caroline Burton have no conflicts of interest or funding sources to declare. 


\section{References}

1. Ledford H. Melanoma drug wins US approval. Nature. 2011;471(7340):561

2. Ribas A. Clinical development of the anti-CTLA-4 antibody tremelimumab. Semin Oncol. 2010;37(5):450-454

3. Hodi FS, O'Day SJ, McDermott DF, et al. Improved survival with ipilimumab in patients with metastatic melanoma. N Engl J Med. 2010;363(8):711-723.

4. Brahmer J, Reckamp KL, Baas $P$, et al. Nivolumab versus Docetaxel in Advanced Squamous-Cell Non-Small-Cell Lung Cancer. N Engl J Med. 2015;373(2):123-135.

5. Motzer RJ, Rini BI, McDermott DF, et al. Nivolumab for Metastatic Renal Cell Carcinoma: Results of a Randomized Phase II Trial. J Clin Oncol. 2015;33(13):1430-1437.

6. Powles T, Eder JP, Fine GD, et al. MPDL3280A (anti-PD-L1) treatment leads to clinical activity in metastatic bladder cancer. Nature. 2014;515(7528):558-562.

7. Massard C, Gordon MS, Sharma S, et al. Safety and Efficacy of Durvalumab (MEDI4736), an Anti-Programmed Cell Death Ligand-1 Immune Checkpoint Inhibitor, in Patients With Advanced Urothelial Bladder Cancer. J Clin Oncol. 2016:34(26):3119-3125

8. Ferris RL, Blumenschein G Jr, Fayette J, et al. Nivolumab for Recurrent Squamous-Cell Carcinoma of the Head and Neck. N Engl J Med. 2016;375(19):1856-1867

9. Le DT, Uram JN, Wang H, et al. PD-1 Blockade in Tumors with Mismatch-Repair Deficiency. N Engl J Med. 2015;372(26):2509-2520.

10. Ansell SM, Lesokhin AM, Borrello I, et al. PD-1 blockade with nivolumab in relapsed or refractory Hodgkin's lymphoma. N Engl J Med. 2015;372(4): 311-319.

11. El-Khoueiry AB, Sangro B, Yau T, et al. Nivolumab in patients with advanced hepatocellular carcinoma (CheckMate 040): an open-label, non-comparative, phase 1/2 dose escalation and expansion trial. Lancet. 2017;389(10088) 2492-2502.

12. Friedman CF, Proverbs-Singh TA, Postow MA. Treatment of the Immune-Related Adverse Effects of Immune Checkpoint Inhibitors: A Review. JAMA Oncol. 2016;2(10):1346-1353.

13. Heinzerling L, Goldinger SM. A review of serious adverse effects under treatment with checkpoint inhibitors. Curr Opin Oncol. 2017;29(2):136-144.

14. Kahler KC, Hauschild A. Treatment and side effect management of CTLA4 antibody therapy in metastatic melanoma. J Dtsch Dermatol Ges. 2011;9(4):277-286.

15. Weber JS, Postow M, Lao CD, Schadendorf D. Management of Adverse Events Following Treatment With Anti-Programmed Death-1 Agents. Oncologist. 2016;21(10):1230-1240.

16. Bertrand A, Kostine M, Barnetche T, Truchetet ME, Schaeverbeke T. Immune related adverse events associated with anti-CTLA-4 antibodies: systematic review and meta-analysis. BMC Med. 2015;13:211-224.

17. Abdel-Wahab N, Shah M, Suarez-Almazor ME. Adverse Events Associated with Immune Checkpoint Blockade in Patients with Cancer: A Systematic Review of Case Reports. PLoS One. 2016;11(7):e0160221. doi:10.1371/journal. pone.0160221

18. Naidoo J, Page DB, Li BT, et al. Toxicities of the anti-PD-1 and anti-PD-L1 immune checkpoint antibodies. Ann Oncol. 2015;26(12):2375-2391.

19. Gupta A, De Felice KM, Loftus EV Jr, Khanna S. Systematic review: colitis associated with anti-CTLA-4 therapy. Aliment Pharmacol Ther. 2015;42(4):406-417.

20. Pernot S, Ramtohul T, Taieb J. Checkpoint inhibitors and gastrointestinal im mune-related adverse events. Curr Opin Oncol. 2016;28(4):264-268.

21. Kamata T, Suzuki A, Mise N, et al. Blockade of programmed death-1/programmed death ligand pathway enhances the antitumor immunity of human invariant natural killer T cells. Cancer Immunol Immunother. 2016;65(12): 1477-1489.

22. Pardoll DM. The blockade of immune checkpoints in cancer immunotherapy Nat Rev Cancer. 2012;12(4):252-264

23. Velu V, Titanji K, Zhu B, et al. Enhancing SIV-specific immunity in vivo by PD-1 blockade. Nature. 2009:458(7235):206-210.

24. Phan GQ, Yang JC, Sherry RM, et al. Cancer regression and autoimmunity induced by cytotoxic $T$ lymphocyte-associated antigen 4 blockade in patients with metastatic melanoma. Proc Natl Acad Sci U S A. 2003;100(14): 8372-8377.

25. U.S. Food and Drug Administration, Center for Drug Evaluation and Research. Atezolizumab BLA 761041 approval letter (urothelial carcinoma) https://www.genentech-access.com/content/dam/gene/accesssolutions/ brands/tecentriq/Appeals\%20Tips/TECENTRIQ-FDA-Approval-Letter-Met astatic-Urothelial-Carcinoma-First-Line-Therapy.pdf. Accessed September 30, 2017.

26. U.S. Food and Drug Administration, Center for Drug Evaluation and Research. Imfinzi (durvalumab) approval letter. https://www.accessdata.fda. gov/drugsatfda_docs/appletter/2017/7610690rig1s000ltr.pdf. Accessed September 30, 2017

27. U.S. Food and Drug Administration, Center for Drug Evaluation and Research. Bavencio (avelumab) accelerated approval letter - urothelial carcinoma. https://www.accessdata.fda.gov/drugsatfda_docs/appletter/2017/ 761078Orig1s000ltr.pdf. Accessed May 16, 2017

28. U.S. Food and Drug Administration, Center for Drug Evaluation and Research. Atezolizumab BLA 761041 approval letter (NSCLC). https://www.accessdata.fda.gov/drugsatfda_docs/nda/2016/761034Orig1s000Approv.pdf. Accessed April 6, 2017.

29. U.S. Food and Drug Administration, Center for Drug Evaluation and Research. Bavencio (avelumab) approval letter - Merkel cell carcinoma. https:// www.accessdata.fda.gov/drugsatfda_docs/appletter/2017/761049Orig1s000ltr.pdf. Accessed April 27, 2017

30. U.S. Food and Drug Administration, Center for Drug Evaluation and Research. Atezolizumab BLA 761041 approval letter. https://www.accessdata. fda.gov/drugsatfda_docs/nda/2016/761034Orig1s000Approv.pdf. Accessed April 6, 2017.

31. Voskens CJ, Goldinger SM, Loquai $C$, et al. The price of tumor control: an analysis of rare side effects of anti-CTLA-4 therapy in metastatic melanoma from the ipilimumab network. PLoS One. 2013;8(1):e53745. doi:10.1371/journal.pone.0053745

32. Larkin J, Chiarion-Sileni V, Gonzalez R, et al. Combined Nivolumab and Ipilimumab or Monotherapy in Untreated Melanoma. $N$ Engl J Med. 2015;373(1):23-34.

33. Michot JM, Bigenwald C, Champiat S, et al. Immune-related adverse events with immune checkpoint blockade: a comprehensive review. Eur J Cancer. 2016;54:139-148.

34. Villadolid J, Amin A. Immune checkpoint inhibitors in clinical practice: update on management of immune-related toxicities. Transl Lung Cancer Res. 2015;4(5):560-575

35. Weber JS, Kahler KC, Hauschild A. Management of immune-related adverse events and kinetics of response with ipilimumab. J Clin Oncol. 2012;30(21):2691-2697

36. Kahler KC, Hassel JC, Heinzerling L, et al. Management of side effects of immune checkpoint blockade by anti-CTLA-4 and anti-PD-1 antibodies in metastatic melanoma. J Dtsch Dermatol Ges. 2016;14(7):662-681.

37. Postow MA. Managing immune checkpoint-blocking antibody side effects. Am Soc Clin Oncol Educ Book. 2015:76-83.

38. Lacouture ME, Wolchok JD, Yosipovitch G, Kahler KC, Busam KJ, Hauschild A. Ipilimumab in patients with cancer and the management of dermatologic adverse events. J Am Acad Dermatol. 2014;71(1):161-169.

39. Robert C, Schachter J, Long GV, et al. Pembrolizumab versus Ipilimumab in Advanced Melanoma. N Engl J Med. 2015;372(26):2521-2532.

40. Weber J. Ipilimumab: controversies in its development, utility and autoimmune adverse events. Cancer Immunol Immunother. 2009;58(5):823-830.

41. Beck KE, Blansfield JA, Tran KQ, et al. Enterocolitis in patients with cancer after antibody blockade of cytotoxic T-lymphocyte-associated antigen 4. J Clin Oncol. 2006;24(15):2283-2289.

42. Cancer Therapy Evaluation Program, National Cancer Institute (NCI). Common terminology criteria for adverse events v3.0 (CTCAE). https://ctep.cancer.gov/protocoldevelopment/electronic_applications/docs/ctcaev3.pdf. Accessed April 9, 2017.

43. De Velasco G, Je Y, Bosse D, et al. Comprehensive Meta-analysis of Key Immune-Related Adverse Events from CTLA-4 and PD-1/PD-L1 Inhibitors in Cancer Patients. Cancer Immunol Res. 2017;5(4):312-318

44. McCutcheon JL, McClain CM, Puzanov I, Smith TA. Infectious Colitis Associated With Ipilimumab Therapy. Gastroenterology Res. 2014;7(1):28-31.

45. Berman D, Parker SM, Siegel J, et al. Blockade of cytotoxic T-lymphocyte antigen-4 by ipilimumab results in dysregulation of gastrointestinal immunity in patients with advanced melanoma. Cancer Immun. 2010;10:11-20.

46. Reynolds K, Ananthakrishnan A, Dougan M, Bardia A. Immune-Related Adverse Events (irAEs) in Cancer Patients. In: McKean SC, Ross JJ, Dressler DD, Scheurer DB, eds. Principles and Practice of Hospital Medicine. 2nd ed. New York: McGraw-Hill Education; 2017

47. Garcia-Neuer M, Marmarelis ME, Jangi SR, et al. Diagnostic Comparison of CT Scans and Colonoscopy for Immune-Related Colitis in Ipilimumab-Treated Advanced Melanoma Patients. Cancer Immunol Res. 2017:5(4):286-291.

48. Venditti $O$, De Lisi D, Caricato $M$, et al. Ipilimumab and immune-mediated adverse events: a case report of anti-CTLA4 induced ileitis. BMC Cancer. 2015;15:87-91.

49. Messmer M, Upreti S, Tarabishy Y, et al. Ipilimumab-Induced Enteritis without Colitis: A New Challenge. Case Rep Oncol. 2016;9(3):705-713. 
50. De Felice KM, Gupta A, Rakshit S, et al. Ipilimumab-induced colitis in patients with metastatic melanoma. Melanoma Res. 2015;25(4):321-327.

51. Baden LR, Swaminathan S, Angarone M, et al. Prevention and Treatment of Cancer-Related Infections, Version 2.2017, NCCN Clinical Practice Guidelines in Oncology. J Natl Compr Canc Newt. 2017;14(7):882-913.

52. Minor DR, Chin K, Kashani-Sabet M. Infliximab in the treatment of anti-CTLA4 antibody (ipilimumab) induced immune-related colitis. Cancer Biother Radiopharm. 2009:24(3):321-325.

53. Merrill SP, Reynolds P, Kalra A, Biehl J, Vandivier RW, Mueller SW. Early administration of infliximab for severe ipilimumab-related diarrhea in a critically ill patient. Ann Pharmacother. 2014;48(6):806-810.

54. Pages C, Gornet JM, Monsel G, et al. Ipilimumab-induced acute severe colitis treated by infliximab. Melanoma Res. 2013;23(3):227-230.
55. Weber J, Thompson JA, Hamid O, et al. A randomized, double-blind, placebo-controlled, phase II study comparing the tolerability and efficacy of ipilimumab administered with or without prophylactic budesonide in patients with unresectable stage III or IV melanoma. Clin Cancer Res. 2009;15(17): 5591-5598.

56. Horvat TZ, Adel NG, Dung TO, et al. Immune-Related Adverse Events, Need for Systemic Immunosuppression, and Effects on Survival and Time to Treatment Failure in Patients With Melanoma Treated With Ipilimumab at Memorial Sloan Kettering Cancer Center. J Clin Oncol. 2015;33(28):3193-3198.

57. Cancer Therapy Evaluation Program, National Cancer Institute (NCl). Common terminology criteria for adverse events v3.0 (CTCAE). https://ctep.cancer.gov/protocoldevelopment/electronic_applications/docs/ctcaev3.pdf. Accessed April 9, 2017. 